\title{
SISTEM PREDIKSI FUZZY TIME SERIES DAN PERANGKINGAN WEIGHTED PRODUCT PADA PENJUALAN ES BUAH
}

\author{
Heffi Awang Cahya ${ }^{1}$, Resty Wulanningrum², Danar Putra Pamungkas ${ }^{3}$ \\ 1Program Studi Teknik Informatika, Universitas Nusantara PGRI Kediri \\ Jln. KH Achmad Dahlan No. 76, Mojoroto, Kota Kediri \\ heffiawang@gmail.com
}

\begin{abstract}
At every start a new business, especially the sale of fruit ice must always pay attention to profit and loss to ensure the continuity of the business, because the true purpose of entrepreneurship is to seek profit. One of the things that can be done is to predict sales profits appropriately so that the seller can determine what to do in the future. Another factor that is also very important is the ranking of the most desirable fruits, because knowing the seller's favorite fruit ranking can determine the stock of fruit which can also affect sales profits. The research, entitled Fuzzy Time Series Prediction System and Weighted Product Ranking in Fruit Ice Sales, is designed to create a system that can predict sales profits every week. This system can also rank customers' favorite fruits in order to determine the stock of the favorite and non-favorite fruit. The results of the calculation of the error value on the prediction of profits obtained the lowest value of $0.21 \%$ and for ranking obtained the lowest error value of $0.40 \%$ which means the lower the error value obtained, the higher the prediction accuracy.
\end{abstract}

Keywords: Forecast, Fuzzy, Ranking, Weighted Product

\begin{abstract}
Abstrak
Di setiap memulai usaha baru terutama penjualan es buah harus selalu memperhatikan laba maupun rugi untuk menjamin kelangsungan usahanya, karena sejatinya tujuan berwirausaha adalah mencari keuntungan. Salah satu hal yang bisa dilakukan yaitu dengan cara memprediksi keuntungan penjualan secara tepat agar penjual dapat menentukan apa yang harus dilakukan kedepannya. Faktor lain yang juga sangat penting yaitu peringkat buah yang paling diminati, karena dengan mengetahui rangking buah favorit penjual bisa menentukan stok buah yang juga dapat mempengaruhi keuntungan penjualan. Penelitian dengan judul Sistem Prediksi Fuzzy Time Series Dan Perangkingan Weighted Product Pada Penjualan Es Buah ini, dirancang untuk membuat sistem yang dapat memprediksi keuntungan penjualan tiap minggunya. Sistem ini juga dapat merangking buah favorit pelanggan agar dapat menentukan stok buah yang menjadi favorit maupun yang bukan favorit. Hasil perhitungan nilai error pada prediksi keuntungan diperoleh nilai terendah yaitu 0,21\% dan untuk perangkingan diperoleh nilai error terendah sebesar 0,40\% yang berarti semakin rendah nilai error yang diperoleh maka semakin tinggi akurasi prediksinya.
\end{abstract}

Kata kunci: Prediksi, Fuzzy, Perangkingan, Weighted Product

Fuzzy Time Series Dan Weighted Product Pada Penjualan Es Buah (Heffi Awang Cahya)|103 


\section{PENDAHULUAN}

Di setiap memulai usaha baru terutama penjualan es buah harus selalu memperhatikan laba maupun rugi untuk menjamin kelangsungannya, karena sejatinya tujuan berwirausaha adalah mencari keuntungan. Salah satu hal yang bisa dilakukan yaitu dengan cara memprediksi keuntungan penjualan secara tepat agar penjual dapat menentukan apa yang harus dilakukan kedepannya. Untuk mendukung hal itu maka penjual harus bisa membuat dagangannya laku.

Demi menarik minat pelanggan, maka penjual harus membuat tampilan produknya semenarik mungkin. Tampilan produk merupakan salah satu faktor yang mempengaruhi minat pelanggan dalam berbelanja secara online. Faktor lain yang juga sangat penting yaitu peringkat buah favorit yang paling diminati. Hal tersebut memang sangat mempengaruhi, karena dengan mengetahui rangking buah favorit penjual bisa menentukan stok buah yang juga dapat mempengaruhi keuntungan penjualan.

Berdasarkan penelitian oleh Rodiza Ayuni Forin Saputri pada tahun 2019 dengan judul Penerapan Metode Fuzzy Time Series (FTS) Untuk Prediksi Penjualan Berbasis Web Pada Toko Grosir 3 Roda Sengkaling, memiliki hasil perhitungan akurasi keakuratan sebesar 99,3\% berdasarkan data penjualan dari bulan februari 2017 sampai September 2018 dapat meminimalisir penumpukan stok barang [1].

Selain itu penelitian yang dilakukan oleh Cepi Rahmat Hidayat, Teuku Mufizar dan Muhamad Dadan Ramdani pada tahun 2018 dengan judul Implementasi Metode Weighted Product (WP) Pada Sistem Pendukung Keputusan Seleksi Calon Karyawan BPJS Kesehatan Tasikmalaya mampu menyediakan alternatif pilihan dengan efektif dan mengurangi unsur subyektifitas dengan margin of error $90 \%$ jika dibandingkan dengan sistem seleksi yang lama [2], [8].

Perbedaan penelitian ini dengan penelitian sebelumnya yaitu, menggunakan metode fuzzy time series untuk memprediksi keuntungan penjualan es buah setiap minggunya, serta metode weighted product untuk merangking buah favorit pelanggan. Dimana dua metode ini saling berhubungan dalam menentukan persediaan buah setiap minggunya dengan tetap memperhitungkan keuntungan penjualan.

\section{METODOLOGI PENELITIAN}

\subsection{Teori Penunjang}

a. Penjualan: Penjualan adalah suatu transaksi yang bertujuan untuk mendapatkan suatu keuntungan, dan merupakan suatu jantung dari suatu perusahaan. Dengan pengertian lain definisi penjualan adalah pemindahan hak milik atas barang atau pemberian jasa yang dilakukan penjualan kepada pembeli dengan harga yang disepakati bersama dengan jumlah yang dibebankan kepada pelanggan dalam penjualan barang atau jasa dalam suatu periode akuntansi [4].

b. Prediksi Keuntungan: Laba merupakan selisih positif antara pendapatan dalam suatu periode dan biaya yang dikeluarkan untuk mendatangkan laba. 
Pengertian laba yang dianut oleh struktur akuntansi sekarang ini adalah laba akuntansi yang merupakan selisih pengukuran pendapatan dan biaya [5].

c. Fuzzy Time Series: Data berkala adalah data yang dikumpulkan dari waktu ke waktu, untuk menggambarkan perkembangan suatu kegiatan. Analisis data berkala memungkinkan kita untuk mengetahui perkembangan suatu atau beberapa kejadian serta hubungan/pengaruhnya terhadap kejadian lainnya [6].

Langkah-langkah proses peramalan pada metode fuzzy time series, yaitu:

1) Mendefinisikan semesta pembicaraan (himpunan semesta $U$ ) dari variasi data historisnya.

2) Mempartisi $U$ menjadi panjang interval yang sama.

3) Mendefinisikan himpunan fuzzy $A i$

4) Memfuzzykan variasi dari data historis peramalan.

5) Menyatakan relasi fuzzy logic $A i \rightarrow A j$

6) Menjadikan relasi fuzzy orde pertama, menjadi suatu grup relasi fuzzy logic jika memiliki sisi kanan yang sama, menghitung relasi $R i$ untuk setiap fuzzy ke-i.

7) Meramalkan output peramalannya dan mendefuzifikasikannya [7].

d. Weighted Product: Metode Weighted Product (WP) merupakan perkalian untuk menghubungkan rating atribut, dimana rating setiap atribut harus dipangkatkan dengan bobot atribut yang bersangkutan. Metode weighted product memerlukan proses normalisasi karena metode ini mengalikan hasil penilaian setiap atribut. Hasil perkalian tersebut belum bermakna jika belum dibandingkan dengan nilai standar. Bobot untuk atribut manfaat berfungsi sebagai pangkat positif dalam proses perkalian, sementara bobot biaya berfungsi sebagai pangkat negatif [8].

Langkah-langkah dalam metode WP adalah:

1) Menentukan Alternatif (A).

2) Menentukan Kriteria (C).

3) Menentukan tingkat kepentingan suatu kriteria.

4) Menentukan bobot (W).

5) Menentukan nilai setiap alternatif di setiap kriteria.

6) Menentukan kategori di setiap kriteria. Berpangkat negatif bila termasuk kategori biaya, dan berpangkat positif bila termasuk kategori keuntungan.

7) Melakukan perbaikan bobot $(\Sigma w=1)$.

8) Menghitung Vektor S.

9) Menghitung nilai Vektor $V$ yang akan digunakan untuk perankingan.

10) Nilai Vi yang terbesar mengindikasikan bahwa Ai adalah yang lebih dipilih [8].

e. Mean Absolute Percentage Error: merupakan pengukuran kesalahan yang menghitung ukuran presentase penyimpangan antara data aktual dengan data peramalan [8]. 


\subsection{Metode Penelitian}

a. Analisa dan Pengumpulan Data: Pengumpulan data prediksi keuntungan dengan cara bertanya langsung kepada penjual es buah disatu tempat yang ada di jl. dr. saharjo kota kediri, sedangkan data untuk perangkingan dengan cara membuat kuesioner yang diisi oleh pembeli yang datang ke outlet secara langsung.

Tabel 1. Data Prediksi Keuntungan

\begin{tabular}{cccc}
\hline Tahun & Bulan & Minggu & Data Keuntungan (ribu) \\
\hline 2019 & Oktober & 1 & 521 \\
2019 & Oktober & 2 & 462 \\
2019 & Oktober & 3 & 483 \\
2019 & Oktober & 4 & 479 \\
2019 & November & 1 & 503 \\
2019 & November & 2 & 472 \\
2019 & November & 3 & 495 \\
2019 & November & 4 & 486 \\
\hline
\end{tabular}

Data keuntungan penjualan yang digunakan adalah keuntungan mingguan yaitu mulai bulan Oktober sampai November. Data keuntungan penjualan pada Tabel 1. diperoleh dari hasil wawancara.

Tabel 2. Kriteria Kesegaran Buah

\begin{tabular}{ccc}
\hline Kriteria & Kesegaran Buah & Bobot \\
\hline \multirow{2}{*}{ C1 } & Lunak & 3 \\
& Segar & 2 \\
& Keras & 1 \\
\hline
\end{tabular}

Kriteria dari kesegaran buah ada 3, yaitu terdiri dari lunak yang diberi bobot 3, segar yang diberi bobot 2, dan keras yang diberi bobot 1 .

Tabel 3. Kriteria Tingkat Kemanisan

\begin{tabular}{ccc}
\hline Kriteria & Tingkat Kemanisan & Bobot \\
\hline \multirow{2}{*}{ C2 } & Sangat Manis & 3 \\
& Manis & 2 \\
& Tidak Manis & 1 \\
\hline
\end{tabular}

Kriteria dari tingkat kemanisan ada 3, yaitu terdiri dari sangat manis yang diberi bobot 3 , manis yang diberi bobot 2 , dan tidak manis yang diberi bobot 1 . 
Tabel 4. Kriteria Ukuran Potongan Buah

\begin{tabular}{ccc}
\hline Kriteria & Ukuran Potongan & Bobot \\
\hline \multirow{4}{*}{ C3 } & Sangat Besar & 4 \\
& Besar & 3 \\
& Sedang & 2 \\
& Kecil & 1 \\
\hline
\end{tabular}

Kriteria dari ukuran potongan buah ada 4, yaitu terdiri dari sangat besar yang diberi bobot 4 , besar yang diberi bobot 3 , sedang yang diberi bobot 2 , dan kecil yang diberi bobot 1 .

Tabel 5. Bobot Kriteria Buah

\begin{tabular}{lcccc}
\hline \multicolumn{1}{c}{ Buah } & Alternatif & C1 & C2 & C3 \\
\hline Buah Alpukat & A1 & 3 & 2 & 1 \\
Buah Garbis & A2 & 2 & 2 & 4 \\
Buah Kelapa Muda & A3 & 3 & 1 & 3 \\
Buah Kolang-Kaling & A4 & 1 & 1 & 3 \\
Buah Naga & A5 & 2 & 1 & 2 \\
Buah Nangka & A6 & 3 & 3 & 1 \\
Buah Melon & A7 & 3 & 3 & 2 \\
Buah Semangka & A8 & 2 & 2 & 2 \\
\hline
\end{tabular}

Setelah mendapatkan bobot masing-masing kriteria yang diperoleh dari hasil pengisian kuesioner, buah-buah yang menjadi topping es buah akan dimasukkan bobotnya sesuai kriteria buah dan akan dirangking dengan metode weighted product.

b. Perancangan Sistem: Perancangan sistem pada penelitian ini berdasarkan dari kebutuhan untuk penyelesaian masalah.

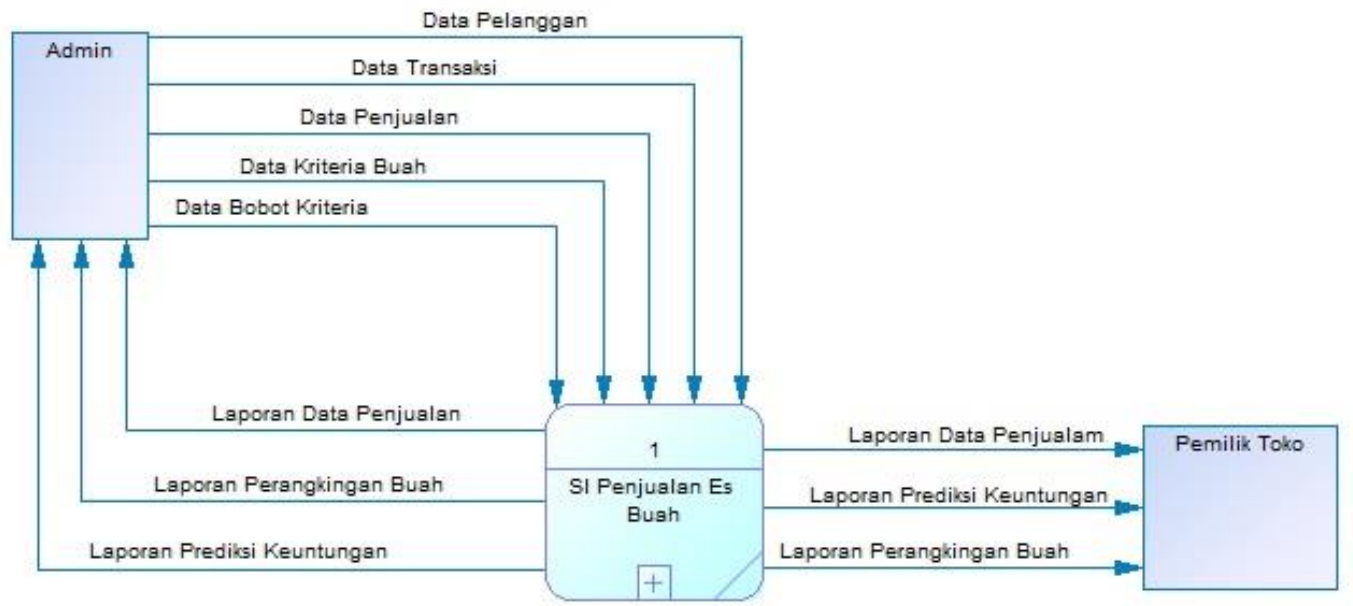

Gambar 1. DFD Level 0

Gambar 1. merupakan DFD level 0 yang menjelaskan hubungan antara Admin dengan Pemilik Toko. Pelanggan tidak termasuk kedalam sistem 
karena interaksi atau cara pemesanannya tidak melalui sistem secara langsung.

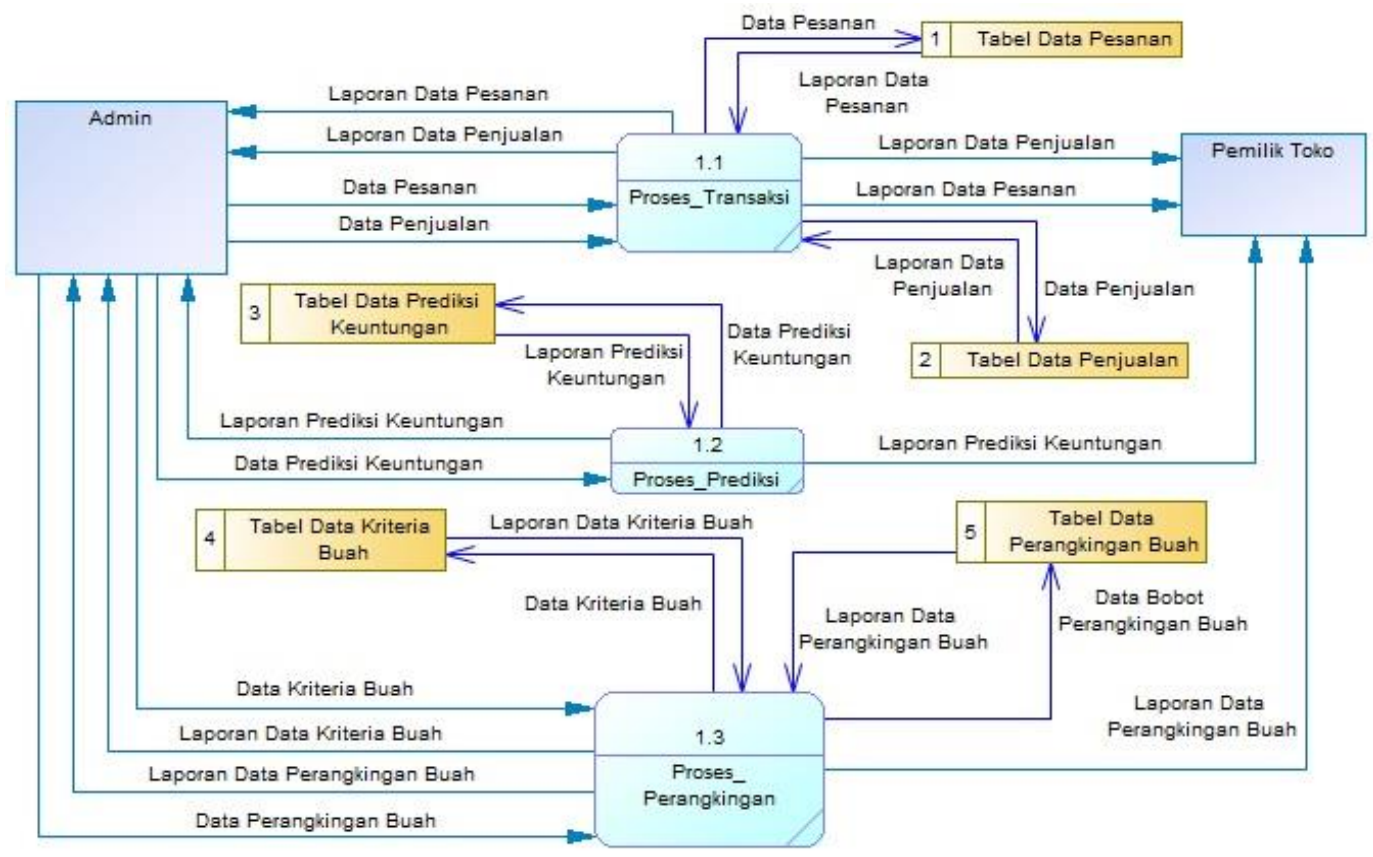

Gambar 2. DFD Level 1

Pada Gambar 2. merupakan DFD level 1 berisi uraian proses-proses yang terdapat pada sistem yaitu proses transaksi, proses prediksi dan proses perangkingan.

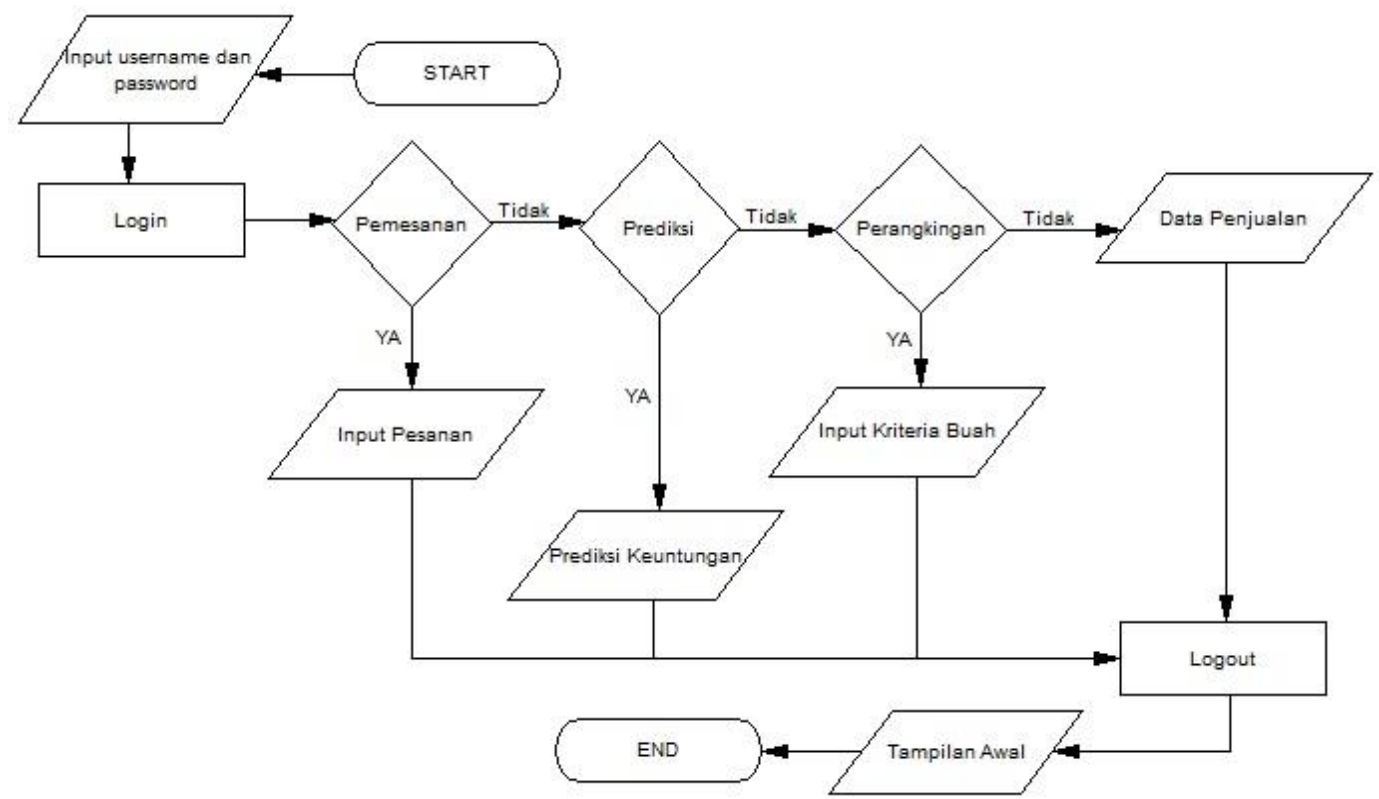

Gambar 3. Flowchart Sistem 
Gambar 3. menjelaskan bagaimana alur dari sistem penjualan ini. User terlebih dahulu login agar bisa mengoperasikan sistem. Di sistem terdapat tiga kegiatan yaitu pemesanan, prediksi dan perangkingan.

c. Pembuatan Sistem: Pembuatan sistem ini berbasis web dengan bahasa pemrograman PHP dan basis data menggunakan Appserv.

d. Implementasi: Mengimplementasikan metode-metode yang ditentukan dalam pembuatan program.

e. Pengujian Sistem: Setelah sistem jadi maka akan dilakukan pengujian pada program tersebut.

f. Debugging: Pada bagian ini yaitu melakukan perbaikan bila ada kesalahan pada sistem yang sudah dibuat.

\section{HASIL DAN PEMBAHASAN}

\subsection{Penyelesaian Prediksi}

Langkah pertama, dari data keuntungan yang akan diprediksi dicari selisih tiap data dan dirata-rata. Selanjutnya rata-rata dibagi 2 sehingga diperoleh panjang interval efektif. Adapun perhitungannya sebagai berikut:

Selisih data yang diperoleh yaitu 59, 21, 4, 24, 31, 23, 9 dengan rata-rata selisih adalah 24,43. Selanjutnya dibagi 2 menjadi 12,2. Pada Tabel 6. Merupakan jangkauan basis interval, sehingga diperoleh nilai 10 sebagai panjang intervalnya.

Tabel 6. Jangkauan Basis Interval

\begin{tabular}{cc}
\hline Jangkauan & Basis \\
\hline $0,1-1,0$ & 0,1 \\
$1,1-10$ & 1 \\
$11-100$ & 10 \\
$101-1000$ & 100 \\
\hline
\end{tabular}

Langkah kedua, mencari jumlah interval dari nilai maksimum dikurangi nilai minimum lalu dibagi panjang interval maka diperoleh range intervalnya sebagai berikut:

$$
\text { range interval }=\frac{\max -\min }{\text { interval }}=\frac{521-462}{10}=5,9
$$

Tabel 7. Range Interval

\begin{tabular}{cc}
\hline Semesta & Range \\
\hline U1 & $462-472$ \\
U2 & $472,1-482$ \\
U3 & $482,1-492$ \\
U4 & $492,1-502$ \\
U5 & $502,1-512$ \\
U6 & $512,1-522$ \\
\hline
\end{tabular}


Langkah ketiga, dari interval tersebut terbentuk himpunan fuzzy Ai yang menunjukkan keanggotaan dari uj. Bagian ini disebut fuzzifikasi. Adapun data aktualnya sebagai berikut:

Tabel 8. Data Aktual

\begin{tabular}{cccc}
\hline Bulan & Minggu & Data Aktual & Fuzzifikasi \\
\hline Oktober & 1 & 521 & A6 \\
Oktober & 2 & 462 & A1 \\
Oktober & 3 & 483 & A3 \\
Oktober & 4 & 479 & A2 \\
November & 1 & 503 & A5 \\
November & 2 & 472 & A1 \\
November & 3 & 495 & A4 \\
November & 4 & 486 & A3 \\
\hline
\end{tabular}

Langkah keempat, menentukan fuzzy logical relationship (FLR) dari data diatas. Sisi kiri disebut current state dan sisi kanan disebut next state atau bisa dituliskan $\mathrm{Aj} \rightarrow \mathrm{Ak}$.

\begin{tabular}{c} 
Tabel 9. Fuzzy Logical Relationship \\
\hline Fuzzy Logical Relationship (FLR) \\
\hline $\mathrm{A} 6 \rightarrow \mathrm{A} 1$ \\
$\mathrm{~A} 1 \rightarrow \mathrm{A} 3$ \\
$\mathrm{~A} 3 \rightarrow \mathrm{A} 2$ \\
$\mathrm{~A} 2 \rightarrow \mathrm{A} 5$ \\
$\mathrm{~A} 5 \rightarrow \mathrm{A} 1$ \\
$\mathrm{~A} 1 \rightarrow \mathrm{A} 4$ \\
$\mathrm{~A} 4 \rightarrow \mathrm{A} 3$
\end{tabular}

Langkah kelima, membagi FLR berdasarkan current state. Lalu diperoleh fuzzy logical relationship group (FLRG) sebagai berikut:

\begin{tabular}{cc} 
Tabel 10. Fuzzy Logical Relationship Group \\
\hline Fuzzy Logical Relationship Group (FLRG) \\
\hline Group 1 & $\mathrm{A} 1 \rightarrow \mathrm{A} 3, \mathrm{~A} 4$ \\
Group 2 & $\mathrm{~A} 2 \rightarrow \mathrm{A} 5$ \\
Group 3 & $\mathrm{~A} 3 \rightarrow \mathrm{A} 2$ \\
Group 4 & $\mathrm{A} 4 \rightarrow \mathrm{A} 3$ \\
Group 5 & $\mathrm{~A} 5 \rightarrow \mathrm{A} 1$ \\
Group 6 & $\mathrm{A} 6 \rightarrow \mathrm{A} 1$ \\
\hline
\end{tabular}

Langkah keenam, menghitung prediksi atau defuzzifikasi dari FLRG yang telah dibentuk dengan prinsip berikut:

a. Jika hanya ada satu FLR pada FLRG: $A j \rightarrow A k$, maka hasil prediksi pada minggu i+1 adalah nilai tengah dari mk yang terdapat pada uk. 
b. Jika terdapat lebih dari satu FLR pada FLRG: Aj $\rightarrow$ Ak1, Ak2, ..., Akp. Maka hasil prediksi pada minggu i+1 yaitu $(\mathrm{m} 1+\mathrm{m} 2+\ldots+\mathrm{mp}) / 2$.

c. Jika tidak ada sama sekali FLR dengan current state berupa Aj, maka hasil prediksi pada minggu i+1 yaitu mj.

Berikut adalah hasil perhitungan prinsip menghitung prediksi:

Tabel 11. Defuzzifikasi

\begin{tabular}{cc}
\hline Current State & Prediksi (ribu) \\
\hline A1 & 488 \\
A2 & 503 \\
A3 & 479 \\
A4 & 486 \\
A5 & 472 \\
A6 & 462 \\
\hline
\end{tabular}

Berdasarkan hasil defuzzifikasi tiap grup maka hasil prediksi untuk tiap data adalah sebagai berikut:

Tabel 12. Hasil Prediksi

\begin{tabular}{ccccc}
\hline Tahun & Bulan & Minggu & $\begin{array}{c}\text { Data } \\
\text { Keuntungan } \\
\text { (ribu) }\end{array}$ & $\begin{array}{c}\text { Hasil } \\
\text { Prediksi } \\
\text { (ribu) }\end{array}$ \\
\hline 2019 & Oktober & 1 & 521 & - \\
2019 & Oktober & 2 & 462 & 487 \\
2019 & Oktober & 3 & 483 & 503 \\
2019 & Oktober & 4 & 479 & 472 \\
2019 & November & 1 & 503 & 488 \\
2019 & November & 2 & 472 & 486 \\
2019 & November & 3 & 495 & 479 \\
2019 & November & 4 & 486 & 497 \\
2019 & Desember & 1 & - & 492 \\
\hline
\end{tabular}

Mencari nilai error menggunakan MAPE dengan rumus sebagai berikut:

MAPE $=\frac{\sum_{t=1}^{n} \frac{\mid X t-S t]}{X t}}{n} \times 100 \%$

Keterangan:

$\mathrm{Xt} \quad$ : Nilai data aktual pada periode $\mathrm{t}$

St : Nilai hasil peramalan pada periode $t$

$\mathrm{t}$ : Periode peramalan

n : Banyaknya data 
Berikut adalah persentase error prediksi tiap minggunya:

Tabel 13. Presentase Error Prediksi

\begin{tabular}{cccccc}
\hline Tahun & Bulan & Minggu & $\begin{array}{c}\text { Data } \\
\text { Keuntungan } \\
\text { (ribu) }\end{array}$ & $\begin{array}{c}\text { Hasil } \\
\text { Prediksi } \\
\text { (ribu) }\end{array}$ & $\begin{array}{c}\text { Nilai } \\
\text { MAPE }\end{array}$ \\
\hline 2019 & Oktober & 1 & 521 & - & - \\
2019 & Oktober & 2 & 462 & 487 & $0,77 \%$ \\
2019 & Oktober & 3 & 483 & 503 & $0,59 \%$ \\
2019 & Oktober & 4 & 479 & 472 & $0,21 \%$ \\
2019 & November & 1 & 503 & 488 & $0,43 \%$ \\
2019 & November & 2 & 472 & 486 & $0,42 \%$ \\
2019 & November & 3 & 495 & 479 & $0,46 \%$ \\
2019 & November & 4 & 486 & 497 & $0,32 \%$ \\
2019 & Desember & 1 & - & 492 & - \\
\hline
\end{tabular}

Dari Tabel 13. menunjukkan bahwa semakin rendah nilai MAPE yang diperoleh, semakin tinggi akurasi prediksinya. Nilai MAPE terendah yaitu pada bulan oktober minggu keempat dengan sebesar 0,21\%.

\subsection{Penyelesaian Perangkingan}

Setelah mendapatkan bobot masing-masing kriteria yang diperoleh dari hasil pengisian kuesioner, buah-buah yang menjadi topping es buah akan dimasukkan bobotnya sesuai kriteria buah dan akan dirangking dengan metode weighted product sebagai berikut:

$$
w_{J}=\frac{w_{j}}{\Sigma w_{j}}
$$

Wj merupakan bobot index ke j. Jadi untuk W1 yaitu 3, W2 yaitu 3, W3 yaitu 4. $\Sigma W_{j}$ merupakan Jumlah dari W yaitu 3, 3, 4. Maka normalisasi bobotnya menjadi:

$$
\begin{aligned}
& W_{1}=\frac{3}{3+3+4}=\frac{3}{10}=0,3 \\
& W_{2}=\frac{3}{3+3+4}=\frac{3}{10}=0,3 \\
& W_{3}=\frac{4}{3+3+4}=\frac{3}{10}=0,4
\end{aligned}
$$

Berikut hasil normalisasi bobotnya dapat dilihat pada Tabel 14. berikut:

Tabel 14. Hasil Normalisasi Bobot

\begin{tabular}{cc}
\hline Normalisasi Bobot & Nilai \\
\hline$W_{1}$ & 0,3 \\
$W_{2}$ & 0,3 \\
$W_{a}$ & 0,4 \\
\hline
\end{tabular}


Langkah berikutnya yaitu menghitung vektor $\mathrm{S}$ dengan rumus sebagai berikut: $S_{i}=\prod_{\mathrm{j}=1}^{\mathrm{n}} X_{i j w j}$

Keterangan:

$\mathrm{X} \quad$ : Kriteria

j $: 1,2,3$

w : bobot

n : banyaknya kriteria

$$
\begin{aligned}
& S_{1}=\left(3^{0, a}\right)\left(2^{0,3}\right)\left(1^{0,4}\right)=1,712 \\
& S_{2}=\left(2^{0,3}\right)\left(2^{0,8}\right)\left(4^{0,4}\right)=2,639 \\
& S_{a}=\left(3^{0,3}\right)\left(1^{0,3}\right)\left(3^{0,4}\right)=2,158 \\
& S_{4}=\left(1^{0,3}\right)\left(1^{0,8}\right)\left(3^{0,4}\right)=1,551 \\
& S_{5}=\left(2^{0,3}\right)\left(1^{0,8}\right)\left(2^{0,4}\right)=1,624 \\
& S_{6}=\left(3^{0.3}\right)\left(3^{0,8}\right)\left(1^{0,4}\right)=1,933 \\
& S_{7}=\left(3^{0,3}\right)\left(3^{0.3}\right)\left(2^{0,4}\right)=2,551 \\
& S_{\mathrm{g}}=\left(2^{0,8}\right)\left(2^{0,3}\right)\left(2^{0,4}\right)=2
\end{aligned}
$$

Adapun hasil perhitungan vektor $S$ dapat dilihat pada Tabel 15. berikut ini:

\begin{tabular}{cc}
\multicolumn{2}{c}{ Tabel 15 Hasil Perhitungan Vektor S } \\
\hline Vektor $S$ & Nilai \\
\hline$S_{1}$ & 1,712 \\
$S_{2}$ & 2,639 \\
$S_{3}$ & 2,158 \\
$S_{4}$ & 1,551 \\
$S_{5}$ & 1,624 \\
$S_{6}$ & 1,933 \\
$S_{7}$ & 2,551 \\
$S_{8}$ & 2 \\
\hline
\end{tabular}

Setelah itu menghitung vektor $\mathrm{V}$ yang merupakan langkah terakhir dari metode weighted product dengan rumus sebagai berikut:

$V_{i}=\frac{s_{i}}{\Sigma s_{i}}$

Berikut perhitungan masing-masing vektor V:

$$
\begin{aligned}
& V_{1}=\frac{1,712}{1,712+2,639+2,158+1,551+1,624+1,933+2,551+2}=\frac{1,712}{16,168}=0,106 \\
& V_{2}=\frac{2,639}{1,712+2,639+2,158+1,551+1,624+1,933+2,551+2}=\frac{2,639}{16,168}=0.163 \\
& V_{3}=\frac{2,158}{1,712+2,639+2,158+1,551+1,624+1,933+2,551+2}=\frac{2,158}{16,168}=0,133 \\
& V_{4}=\frac{1,551}{1,712+2,639+2,158+1,551+1,624+1,933+2,551+2}=\frac{1,551}{16,168}=0,096 \\
& V_{5}=\frac{1,624}{1,712+2,639+2,158+1,551+1,624+1,933+2,551+2}=\frac{1,624}{16,168}=0,100
\end{aligned}
$$




$$
\begin{aligned}
& V_{6}=\frac{1,933}{1,712+2,639+2,158+1,551+1,624+1,933+2,551+2}=\frac{1,933}{16,168}=0,120 \\
& V_{7}=\frac{2,551}{1,712+2,639+2,158+1,551+1,624+1,933+2,551+2}=\frac{2,551}{16,168}=0,158 \\
& V_{8}=\frac{2}{1,712+2,639+2,158+1,551+1,624+1,933+2,551+2}=\frac{2}{16,168}=0,124
\end{aligned}
$$
berikut:

Maka nilai akhir yang diperoleh oleh masing-masing alternatif (A) sebagai Tabel 16. Hasil Perangkingan Buah Favorit

\begin{tabular}{lccc}
\hline \multicolumn{1}{c}{ Buah } & Alternatif & Nilai & Rangking \\
\hline Buah Alpukat & A1 & 0,106 & 6 \\
Buah Garbis & A2 & 0,163 & 1 \\
Buah Kelapa Muda & A3 & 0,133 & 3 \\
Buah Naga & A4 & 0,096 & 8 \\
Buah Nanas & A5 & 0,100 & 7 \\
Buah Nangka & A6 & 0,120 & 5 \\
Buah Melon & A7 & 0,158 & 2 \\
Buah Semangka & A8 & 0,124 & 4 \\
\hline
\end{tabular}

Mencari persentase nilai error pada perangkingan buah favorit dengan cara nilai mutlak dari rangking sebelumnya dikurangi rangking setelahnya dan dikali 100\%. Adapun hasil presentase nilai errornya sebagai berikut:

Tabel 17. Nilai Error Perangkingan

\begin{tabular}{lcccc}
\hline \multicolumn{1}{c}{ Buah } & Alternatif & Nilai & Rangking & $\begin{array}{c}\text { Nilai } \\
\text { Error }\end{array}$ \\
\hline Buah Garbis & A2 & 0,163 & 1 & $0,40 \%$ \\
Buah Melon & A7 & 0,158 & 2 & $2,50 \%$ \\
Buah Kelapa Muda & A3 & 0,133 & 3 & $0,90 \%$ \\
Buah Semangka & A8 & 0,124 & 4 & $0,40 \%$ \\
Buah Nangka & A6 & 0,120 & 5 & $1,40 \%$ \\
Buah Alpukat & A1 & 0,106 & 6 & $0,60 \%$ \\
Buah Nanas & A5 & 0,100 & 7 & $0,40 \%$ \\
Buah Naga & A4 & 0,096 & 8 & - \\
\hline
\end{tabular}

Dari hasil perhitungan dengan metode weighted product, pada Tabel 17. diperoleh nilai dan rangking dari tiap buah. Dimana buah garbis yang paling menjadi favorit dan buah naga yang paling tidak menjadi favorit. Dengan nilai error terendah yaitu $0,40 \%$.

\section{SIMPULAN}

Berdasarkan hasil analisis dan pengujian metode terhadap penelitian ini, maka dapat ditarik kesimpulan sebagai berikut:

a. Berdasarkan penerapan metode fuzzy time series dalam memprediksi keuntungan penjualan es buah setiap minggunya, diperoleh nilai error 
terendah yaitu sebesar 0,21\%. Dimana semakin rendah nilai error yang diperoleh, maka semakin tinggi akurasi prediksinya.

b. Berdasarkan penerapan metode weighted product dalam perangkingan buah favorit, diperoleh buah yang menjadi favorit yaitu buah garbis dengan nilai perangkingan sebesar 0,163. Sedangkan nilai error terendah pada perangkingan ini yaitu $0,40 \%$.

c. Dalam pengambilan keputusan penentuan modal minggu depan, lebih disarankan penjual menambah stok buah garbis daripada buah yang lain. Dimana hal tersebut mempengaruhi keuntungan pada penjualan es buah karena tidak menjadi boros dalam menentukan penambahan macam-macam stok buah.

\section{DAFTAR PUSTAKA}

[1] R.A.F. Saputri, "Penerapan metode fuzzy time series (FTS) untuk prediksi penjualan berbasis web pada toko grosir 3 roda sengkaling", Jurnal Mahasiswa Teknik Informatika, vol. 3, no.1, pp. 290-297, Mar. 2019.

[2] C.R .Hidayat, T. Mufizar and M.D. Ramdani, "Implementasi metode weighted product (WP) pada sistem pendukung keputusan seleksi calon karyawan BPJS kesehatan tasikmalaya", Konferensi Nasional Sistem Informasi, pp. 530-541, Mar. 2018.

[3] Yakub. Pengantar Sistem Informasi, Graha Ilmu, Yogyakarta, 2012.

[4] A. Prasetya and R. Susanti, "Sistem informasi penjualan berbasis web pada PT. cahaya sejahtera sentosa blitar", Jurnal Ilmiah Teknologi dan Informasia ASIA (JITIKA), vol. 10, no. 2, pp. 1-16, Aug. 2016.

[5] I. Ghozali and A. Chariri, Teori Akuntasi International Financial Reporting System (IFRS), Badan Penerbit Universitas Diponegoro, 2014.

[6] I. Admirani, "Penerapan metode fuzzy time series (FTS) untuk prediksi laba pada perusahaan", JUrnal JUPITER, vol. 10, no. 1, pp. 19-31, Apr. 2018.

[7] M. Muhammad, "Sebaran dan peramalan mahasiswa baru pendidikan matematika universitas muhammadiyah purwokerto dengan metode time invariant fuzzy time series", Matematika Jurnal, vol. III, no. 2, pp. 4858, Sept.2016.

[8] Sarwo and Hermawan, "Prediksi penerimaan siswa baru pada madrasah aliyah as-sayafi'iyah 02 menggunakan metode time series", Jurnal Petir, vol. 9, no. 2, pp. 151-164, Sept. 2016. 